\title{
MEMORIA GEOGRÁFICA EN EL TESTIMONIO CHILENO: ISLA DAWSON
}

\author{
LORETO LÓPEZ G. ${ }^{a} \&$ MARÍA TERESA JOHANSSON M. ${ }^{b}$
}

\begin{abstract}
RESUMEN
El presente artículo analiza la relación entre espacio geográfico y memoria en los testimonios de prisión política que relatan la experiencia de reclusión en el campo de prisioneros de isla Dawson, durante la dictadura cívico-militar chilena. El artículo propone que estos testimonios elaboran una memoria geográfica, manifiesta en el recuerdo del contacto y la relación que los prisioneros establecieron con el contexto geográfico en una de las zonas más australes del mundo. A la vez que, en el marco más amplio de las memorias del terrorismo de Estado, se constituye una memoria del presidio geográfico, en la que confluyen el recuerdo de la violencia con la cual colaboran las condiciones climáticas y topográficas de la isla, junto a experiencias de liberación subjetiva y discreta autonomía, manifiestas en el recuerdo de la contemplación de la naturaleza del entorno, advirtiendo una dimensión benéfica en aquella rememoración. Esto abre la posibilidad de ampliar la relación entre espacio y memoria, en la cual se encuentren el análisis espacial aportado por la geografía y el interés por los procesos de recuerdo propio del campo de estudio de las memorias colectivas.
\end{abstract}

PALABRAS CLAVE: prisión política, memoria, dictadura, terrorismo de Estado, geografía.

\section{GEOGRAPHICAL MEMORY IN THE CHILEAN TESTIMONY: DAWSON ISLAND}

\begin{abstract}
This article analyzes the relationship between geographic space and memory in the testimonies of political prisoners, that relate the experience of detention in the prison camp of Dawson Island, during the Chilean civic-military dictatorship. The article proposes that these testimonies elaborate a geographical memory, manifested in memories of the contact and relationship that the prisoners established with the geographical context in one of the southernmost areas of the

a Programa de Investigación Interdisciplinar en Memoria y Derechos Humanos, Universidad Alberto Hurtado, Proyecto CONICYT DPI 20140048 Tecnologías políticas de la memoria: una genealogía de los dispositivos de registro y denuncia de las violaciones a los derechos humanos durante la dictadura cívico-militar en Chile (1973-2013). $\$ lorelopez@ug.uchile.cl

b Departamento de Literatura, Universidad Alberto Hurtado, Proyecto CONICYT DPI 20140048 Tecnologías políticas de la memoria: una genealogía de los dispositivos de registro y denuncia de las violaciones a los derechos humanos durante la dictadura cívico-militar en Chile (1973-2013). mtjohans@uahurtado.cl
\end{abstract}


world. At the same time, within the broader framework of State terror memories, a memory of the geographic imprisonment is constituted. Here, memories of the violence, with which the climatic and topographic conditions of the island collaborate, appear alongside experiences of subjective liberation and discreet autonomy, manifest in memories of contemplation of nature, noticing a beneficial dimension in that remembrance. This opens the possibility of expanding the relationship between space and memory, where spatial analysis from geography works together with the interest in the processes of remembrance characteristic of the collective memory field of studies.

KEY WORDS: political imprisonment, memory, dictatorship, state terrorism, geography.

"El cielo se nubló en contados minutos y un viento nos tocó violentamente". Aníbal Quijada, Cerco de púas.

\section{INTRODUCCIÓN}

Las narrativas testimoniales junto a los informes de las comisiones de verdad convocadas por el Estado chileno -Comisión Nacional de Verdad y Reconciliación (1990) y Comisión Nacional sobre Prisión Política y Tortura (2003)- han permitido dimensionar y describir una de las formas que adoptó la actividad represiva desplegada por la dictadura cívico-militar chilena (1973-1990) a lo largo y ancho del territorio nacional, materializada en la configuración de una red de al menos 1.132 recintos de detención destinada a todas aquellas personas que el régimen consideró sus opositores políticos. En una de sus modalidades más tempranas, durante los años posteriores al golpe militar del 11 de septiembre de 1973, la estrategia militar de la prisión política aplicada por las Fuerzas Armadas creó diversos campos de prisioneros, esto es, regímenes de deportación y reclusión localizados en distintos espacios geográficos del territorio nacional. En este contexto, los llamados prisioneros de guerra eran aquellos sujetos con existencia legal en su condición de detenidos, sometidos a un régimen de confinamiento en aquellos campos. Un caso emblemático entre los campos de prisioneros fue el emplazado en el territorio insular de isla Dawson, y que fuera el lugar de detención de la

1 En términos generales, estas memorias se construyen estableciendo un límite temporal que va desde el día del Golpe hasta el abandono del poder por parte de las Fuerzas Armadas, excluyendo la referencia a los años previos y posteriores a la dictadura; proponiendo un relato circunscrito a la práctica del terrorismo de Estado; reconociendo centralmente, un tipo de víctima, es decir, quienes padecieron las alta dirigencia política del gobierno de la Unidad Popular y de opositores al régimen provenientes de la región de Magallanes.

La experiencia represiva vivida por miles de chilenosy chilenas durante la dictadura, comoaquella de la prisión política en campos de prisioneros, produjo una profusa narrativa testimonial. En ella, la homologación de experiencias represivas y de selectividad sobre los episodios a narrar, cumplió una importante función de resistencia y denuncia durante la dictadura (Peris Blanes, 2005, 2009a, 2009b, 2011) y los primeros años de la postdictadura chilena, eclipsando la particularidad de los distintos regímenes de detención y de la diversidad de experiencias y memorias que a partir de ellos se elaboraron, prevaleciendo el relato de los hechos trágicos y dolorosos (Montealegre, 2013; Santos, 2017), que hoy caracterizan a las memorias del terrorismo de Estado, y que han devenido en una posición dominante $y$ hegemónica respecto de otras referidas al pasado reciente (Da Silva, 2010, 2013; Winn, 2014) ${ }^{1}$. Sin embargo, en la actualidad, es posible revisitar testimonios de prisión política para comprender nuevas dimensiones de la vivencia y el recuerdo del presidio en campos de prisioneros, al advertir cómo la geografía juega un papel fundamental en ellos, ya sea como parte de la violencia del presidio, reforzando entonces el relato hegemónico del padecimiento, o paradojalmente también

violaciones a los derechos humanos, comenzando por los desaparecidos; estableciendo un concepto de violación a los derechos humanos, que se hace a través de un uso monopólico, pues solo permite referirse al pasado reciente según los límites temporales prescritos; y que finalmente, silencia o margina otro tipo de memorias sobre el período u otras dimensiones de la experiencia represiva. 
como un factor de liberación subjetiva y discreta autonomía. El recuerdo de la dimensión benéfica de la experiencia de contacto con la geografía, se integra a los desplazamientos que se experimentan en el campo de las memorias del pasado reciente, donde se ha comenzado a habilitar una escucha social hacia experiencias del pasado o dimensiones de éstas que habían permanecido eclipsadas, como ha ocurrido con las formas de sobrevivencia en cautiverio, solidaridad e incluso felicidad. Estas son las que Jorge Montealegre ha llamado "memorias eclipsadas" (2013) o "memorias inconvenientes" (2018), "rememoraciones cuya visibilidad es pospuesta en relación a evocaciones que son priorizadas (...). Es decir, en la constelación de rememoraciones hay recuerdos más preteridos que preferidos" (Montealegre, 2018, p. 409).

Para llevar adelante nuestra propuesta, consideramos el análisis de testimonios de prisioneros de guerra confinados en el espacio geográfico de la isla Dawson, en los cuales es posible percibir la relación entre memoria, espacio y geografía. Esta lectura sugiere que el recuerdo de reclusión para estos casos podría entenderse como una memoria geográfica, y a la vez constituirse como una memoria específica dentro del espectro de memorias asociadas a las violaciones a los derechos humanos, que describiremos como memoria del presidio geográfico.

Cabe señalar que pese a la importancia del espacio como categoría que ha intervenido en la consecución de verdad y justicia, y en el desarrollo de lugares de memoria vinculados al recuerdo de las violaciones a los derechos humanos, la relación entre el territorio geográfico y las prácticas represivas de la dictadura ha recibido escasa atención. En consonancia con esto último, limitados han sido los análisis que han interrogado a la memoria espacial de los testimonios de prisión política en su aporte a la conformación de una memoria social.

En la construcción de la memoria colectiva, Maurice Halbwachs advierte que el espacio opera como un marco para la manufactura del recuerdo,

2 El carácter constructivo de la memoria es lo que permite hablar de una manufactura del recuerdo, que según Halbwachs se efectúa según las condiciones del presente. "Si bien lo que vemos hoy se sitúa en el contexto de nuestros recuerdos antiguos, estos recuerdos se adaptan, es decir, como una disposición y parámetro que da forma a la representación del pasado 2 : "hay por un lado un marco espacial, temporal y, más generalmente, social. Este conjunto de representaciones estables y dominantes nos permite en efecto recordar según nuestra voluntad los acontecimientos esenciales de nuestro pasado" (Halbwachs, 2004b, p. 125).

El espacio se constituye como un recurso que permite ordenar el recuerdo a través de la pregunta dónde. Provee de un escenario o punto de referencia de locación para los acontecimientos pasados, a la vez que en sí mismo puede ser recordado como acontecimiento a partir de sus características, lo que contribuye a dotar de atmósfera el recuerdo, ya que "el lugar ha recibido la huella del grupo y a la inversa. Entonces todo lo que hace el grupo puede traducirse en términos espaciales (...)" (Halbwachs, 2004a, p. 133).

La materialización del espacio como marco es lo que se permite el trabajo simbólico que produce lugares de memoria, ya no solo como elemento que organiza el recuerdo, sino que colabora para su escenificación en el paisaje físico del presente. Si los relatos del pasado, como por ejemplo los testimonios, se sitúan e incorporan la referencia a espacios, son estos últimos los que luego presentarán la potencialidad de transformarse en lugares significativos para las memorias que se construyen y conectan a través de los testimonios. Como indica Pierre Nora (2009), los lugares de memoria están marcados por una "intención de memoria", de "detener el tiempo, bloquear el trabajo del olvido, fijar un estado de cosas, inmortalizar la muerte, materializar lo inmaterial (...)" (p. 33). En todo caso en la concepción de Nora la noción de lugar de memoria va más allá de su dimensión geográfica o topográfica, pues con él pueden identificarse elementos materiales, simbólicos y funcionales a los cuales la imaginación les confiere un aura simbólica.

La relación entre memoria y espacio ha resultado de interés para la geografía, en tanto memoria y paisaje constituyen procesos socio-

sin embargo, al conjunto de nuestras percepciones actuales" (Halbwachs, 2004a, p. 25), de ahí que para David Lowenthal el pasado siempre es un "país extraño" (Lowenthal, 1998) 
espaciales (Dwyer \& Alderman, 2008) y porque la pregunta por el tiempo vendría a ser también una interrogación sobre el espacio y el lugar (Geopoetics: Space, Place, and Landscape, 2000). $\mathrm{Si}$ bien se ha observado la manifestación de la memoria en el paisaje a través de prácticas situadas y materialidades que activan el recuerdo, como por ejemplo monumentos, memoriales y nombres de calles (Hoelscher \& Alderman, 2004; Foote \& Azaryahu, 2007; Dwyer \& Alderman, 2008; García, 2009), es posible proponer que antes de su manifestación material en el espacio en forma de marcas, señales o edificaciones, la memoria elabora una imagen del espacio en tanto paisaje del recuerdo.

Se trata del proceso por el cual el recuerdo del espacio queda constituido como paisaje, como apropiación o control representacional de la naturaleza o el entorno (Andermann, 2008), a través de la atribución de significado en tanto componente ideacional de esa representación (Skewes et al. 2011). Pero también se refiere a una construcción derivada de la relación del cuerpo con el espacio a través de experiencias sensoriales que incluyen las emociones, y que lleva a plantear la existencia de smellscape, soundscape y tastescape (Cano, 2015). En este sentido, lo que se ha llamado "paisajes de memoria" (Alderman \& Inwood, 2013; Schindel \& Colombo, 2014) y el "poder nemónico del paisaje" (Andermann, 2012) aluden tanto al conjunto de inscripciones materiales y estéticas que en el espacio actual remiten al pasado o permiten recordar, como a la elaboración misma de la imagen del paisaje a través de la memoria y sus relatos, de esta manera la acción de narrar una historia es en sí misma una forma de recordar en un paisaje (Mate, 2010).

Estas consideraciones nos llevan a plantear que, en los testimonios de presidio político en Chile, y especialmente en aquellos vividos en condiciones geográficas extremas, se construye una memoria geográfica testimonial que ha pasado inadvertida en el estudio de las memorias de la violencia política, y que recupera la relación con el entorno geográfico como parte de la experiencia y el recuerdo. Esta

3 La primera edición del testimonio de Quijada es de 1977 y la de Vuskovic de 1980, este último publicado en italiano. Por su parte, la obra de España es un poemario memoria pondría atención en las particulares condiciones geográficas de presidio, lo cual nos sugiere que el recuerdo de la reclusión podría constituirse además como una memoria específica dentro del espectro de memorias asociadas a las violaciones a los derechos humanos.

El caso de isla Dawson resulta relevante para desarrollar las dimensiones señaladas, por cuanto se trata de un territorio muy particular debido a su aislamiento y ubicación al extremo sur de la ciudad más austral de Chile -Punta Arenas-. De esta manera hemos seleccionado los siguientes testimonios de ex prisioneros de los campamentos de isla Dawson: Cerco de púas de Aníbal Quijada (), Dawson de Sergio Vuskovic (1984), Dawson de Aristóteles España (1985), Dawson Isla 10 de Sergio Bitar $(2011)^{3}$ y Retorno a Dawson de Miguel Lawner (2004). Estos testimonios se inscriben en un amplio corpus de testimonios sobre prisión política chilena que a la fecha supera la centena de títulos publicados en español. Cabe señalar que la narración del presidio en campos de prisioneros y recintos de detención fue mayoritariamente escrita en el exilio, no obstante, ha habido un gran número de testimonios originados durante el fin de la dictadura o en fechas conmemorativas. A lo largo de más de tres décadas, la publicación de estos textos enfrentó dificultades en la recepción y ha generado impacto e incomodidad (Pizarro, 2016), puesto que sus relatos excedían los límites de lo decible (Pollak, 2006).

En sus aspectos esenciales, los testimonios presentaron una narrativa que da cuenta de la experiencia fundamental de la fractura (Epple, 1994), una primacía del sujeto de la enunciación como un tema y perspectiva del discurso y una función referencial relativa a los hechos verificables (Concha, 1978; Jara \& Vidal, 1986; Narváez, 1988). La focalización en la producción testimonial responde a la potencialidad de este género literario para la elaboración de la memoria personal y colectiva (Achugar, 1992; Beverley, 1993), y a su carácter articulador de "(...) un yo plural, representativo de una condición social y de un escenario de luchas políticas" (Jelin, 2002, p. 97).

originalmente editado en 1980 en forma clandestina con el título Equilibrios e Incomunicaciones, y la primera edición del testimonio de Bitar es de 1987. 


\section{LA ISLA DAWSON}

Isla Dawson es una de las 2.532 islas de los archipiélagos de la Región de Magallanes y de la Antártica Chilena, localizadas dentro del área subantártica (Leppe et al. 2007). Ubicada en la parte central del estrecho de Magallanes, se encuentra situada en $54^{\circ}$ de latitud suryentre $70^{\circ}-71^{\circ}$ de longitud oeste, a $100 \mathrm{~km}$ al sur de Punta Arenas. Su extensión es de $1.330 \mathrm{~km}$, con $70 \mathrm{~km}$ de largo por $25 \mathrm{~km}$ en la parte más ancha. La isla fue visitada por distintas expediciones europeas -españolas y británicas-, entre los siglos XVIII y XIX, recibiendo su nombre de la expedición inglesa del comandante Phillip Parker King en 1828, en referencia a un marino de esa época, apellidado Dawson (Astaburuaga, 1899).

En su geografía, Dawson exhibe características contrastantes, pues en la porción norte, el relieve es principalmente bajo, con cerros de poca altura que no superan los 500 metros de elevación, zonas arboladas y algunos valles con bastante agua. Por el contrario, la parte sur se presenta quebrada y casi inabordable por lo abrupto de sus costas, alcanzando las montañas aproximadamente los 1.000 metros de altura (Rapaz, 2000). Desde el punto de vista de sus condiciones ecológicas isla Dawson ha sido descrita como una "encrucijada ambiental" (Legoupil et al. 2011), pues al estar ubicada en una zona de mares interiores exhibe la transición entre el bosque de Nothofagus caducifolio (roble pellín, lenga, ñire y raulí) y el siempreverde. A la vez, en ella se encuentran sectores de turberas propias de la Patagonia y Tierra del Fuego (Schlatter \& Schlatter, 2004). Por su parte, las características climáticas de isla Dawson son las propias del clima

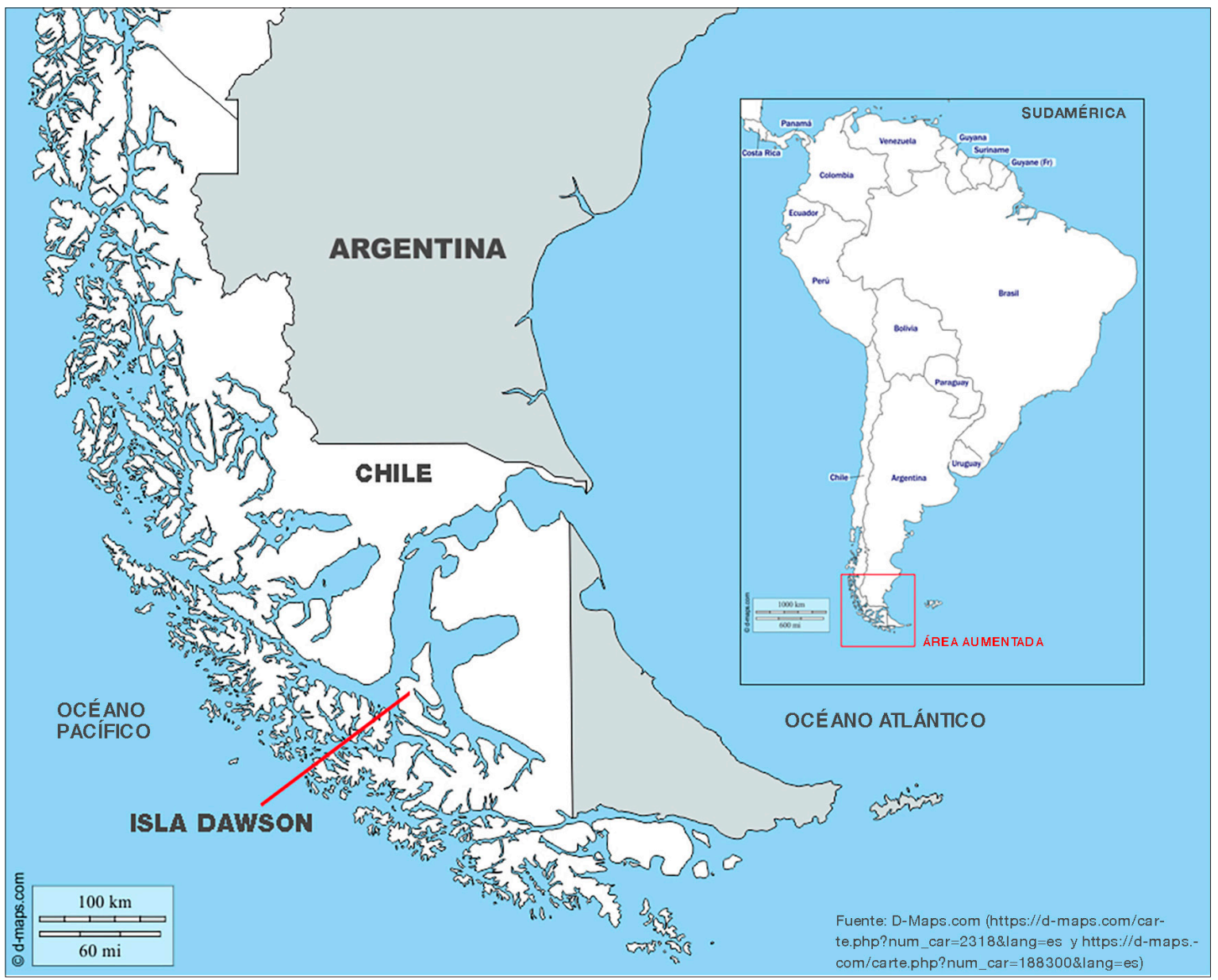

Fig. 1. Localización de isla Dawson. 
templado frío húmedo con predominio oceánico, quedando inmersa en una masa de aire frío en invierno, y fuertes vientos en el verano producto del desplazamiento de un núcleo de aire subtropical hacia el sur (Leppe et al. 2007).

Históricamente la isla había sido habitada por poblaciones originarias ${ }^{4}$, las que comenzaron a declinar al entrar en contacto con la explotación ovejera que se asentó en el lugar durante la segunda mitad del siglo XIX. Para entonces se conocieron los primeros episodios de violencia y brutalidad cuando la población nativa de la región fue perseguida, asesinada y desterrada de sus tierras ancestrales. Esta situación llevó a que en 1889 la orden de los salesianos propusiera la fundación de una misión salvadora en isla Dawson, para refugiar allí a los indígenas perseguidos; sin embargo, hacia 1911 de los 215 que habían sido llevados a la misión solo 25 habían sobrevivido ${ }^{5}$. La misión fue desmantelada y el Estado entregó la isla en concesión a la explotación maderera.

A inicios de los años 70, la Armada chilena presentó un proyecto para hacerse cargo de la isla, a fin de destinarla a instalaciones militares dada su ubicación estratégica en el estrecho de Magallanes. Ello fue aprobado por el gobierno de Salvador Allende, y así en 1972, mediante expropiación de la Estancia Gente Grande amparada en la Ley de Reforma Agraria, Dawson pasó a manos de la Tercera Zona Naval ${ }^{6}$. De esta forma desde fines de 1971 se instaló en la isla una base naval

4 Para mayor detalle sobre poblaciones indígenas que habitaron este espacio geográfico, véase Martinic, 1999 y Legoupil et al 2011.

5 Si bien la isla tiene una ubicación estratégica en cuanto a que se sitúa en medio del territorio de ocupación de los dos pueblos originarios que la misión buscaba salvar, sélknam y kawésqar, ello supuso desarraigarlos de sus respectivos entornos para reunirlos en uno nuevo, lo que unido a la modalidad de trabajo misionero, terminó por acelerar la disminución de la población que se pretendía proteger (Martinic, 2011).

6 Con asiento en la ciudad de Punta Arenas.

7 Este último campo fue encomendado por el Ministerio de Obras Públicas y financiado por la Secretaría Nacional de Detenidos (Cabezas et al. 2017), por medio de la Armada, a la empresa constructora JUPEMAR (González, 2016).

8 En su visita a la isla Dawson el 29 de septiembre de 1973, la Comisión Internacional de la Cruz Roja contó 99 detenidos (Cabezas et al. 2017). Sin embargo distintas fuentes señalan alrededor de 400 hasta 600, véase por de la Compañía de Ingenieros de Infantería de Marina (COMPINGIM) (Rodríguez, 2013). Hasta la actualidad la isla sigue bajo tuición de la Armada.

\section{LOS CAMPOS DE PRISIONEROS}

Isla Dawson albergó a algunos de los primeros campos de prisioneros que funcionaron en Chile luego del Golpe de Estado. "Campo de prisioneros de isla Dawson" es una denominación general que agrupa a dos recintos o campamentos que fueron utilizados en la isla: COMPINGIM, ubicado al norte de Puerto Harris, y que operó entre septiembre y diciembre de 1973; y el Campo de Entrenamiento Río Chico, ubicado en la desembocadura de un riachuelo a unos 20 kilómetros al sur de COMPINGIM, y que funcionó entre diciembre de 1973 y octubre de $1974^{7}$. Ambos recintos estaban situados en la costa sureste de la isla frente al estrecho de Magallanes (Rodríguez, 2013). En isla Dawson habrían permanecido detenidos alrededor de 400 prisioneros, 38 de ellos eran altas autoridades del derrocado gobierno de la Unidad Popular (Cabezas et al. 2017), a quienes se mantuvo segregados del resto de los prisioneros que provenían de la región o de otras partes del país 8 .

El campo de Río Chico disponía de sectores, infraestructura y equipamientos destinados a los detenidos, como barracas, calabozos, baños, cocina y comedores; y al personal de las Fuerzas Armadas a cargo del recinto. El régimen de vida del campo estaba caracterizado por la adopción de

ejemplo Museo virtual de la Memoria y los Derechos Humanos de Magallanes (2019), Dawson 2000 (2003) y Ministerio de Defensa Nacional (2017). El testimonio de Marco Barticevic (2009) consigna que cada una de las cuatro barracas operativas del campamento de Río Chico tenía capacidad para 86 personas, de lo cual se calcula que en él permanecieron al menos 344 prisioneros; no obstante, hace notar que otras tres barracas se encontraban inconclusas, por lo cual el campamento había sido planificado para casi 700 prisioneros (véase pág. 54). Lamentablemente, hasta la fecha, las Fuerzas Armadas y del Orden no han aportado información sobre el número $e$ identidad de las personas que permanecieron detenidas en los distintos lugares utilizados para fines represivos, a la vez que el Informe de la Comisión Nacional sobre Prisión Política y Tortura (2004) tampoco consigna las menciones que cada recinto listado en el Informe recibió por parte de los y las concurrentes a la Comisión, cálculo que no sería difícil de obtener a través de un cruce estadístico. 
ciertas actividades propias de la rutina militar, como el toque de diana a primera hora de la mañana (06:00 AM) para iniciar el día, el alzamiento de la bandera en algunas ocasiones, formación al aire libre para escuchar el discurso de las autoridades, entre otras.

El trabajo forzado formaba parte de la agenda diaria, y éste por lo general se desarrollaba fuera de los límites del recinto. Si bien los prisioneros estaban siempre vigilados y escoltados por personal armado, estas actividades les permitían tener contacto con otros sectores de la isla, el entorno del campo y su paisaje circundante.

Durante las horas destinadas a permanecer al interior del campo, los prisioneros estaban autorizados a organizar actividades colectivas dentro de sus barracas, tales como cursos o charlas preparadas por ellos mismos sobre diversos temas. Además, disponían de tiempo para la lectura, la realización de actividades manuales y también estaban autorizados a recibir correspondencia y encomiendas desde el exterior de la isla. Isla Dawson también recibió visitas de comitivas internacionales $y$ equipos de prensa tanto nacionales como extranjeros, que certificaron la situación de los prisioneros del campo y que contribuyeron a divulgar la existencia de éste más allá de las fronteras nacionales ${ }^{9}$.

De la experiencia en isla Dawson existen diversos testimonios entregados ante comisiones internacionales (como por ejemplo la Comisión Internacional de Investigación de los Crímenes de la Junta Militar en Chile, que sesionó en Helsinki el año 1974), sobre todo por dirigentes de la Unidad Popular, y transcripciones de visitas oficiales que realizaron a los campamentos de prisioneros organismos internacionales; testimonios entregados en el marco de procesos judiciales por secuestro y tortura; testimonios publicados en páginas webs de organismos de derechos humanos y agrupaciones de víctimas; $y$ testimonios escritos y publicados por ex prisioneros, editados en formato libro.

Como se mencionó, en este análisis hemos considerado testimonios escritos y publicados por

9 Los campos de prisioneros recibieron la visita de la Cruz Roja Internacional, en distintas fechas entre septiembre de 1973 y enero de 1974, en ocasiones acompañada por equipos de prensa de Brasil, Inglaterra y Alemania. Por su parte, el diario La Prensa Austral junto a Televisión Nacional efectuó una visita en octubre de 1973, véase cinco ex prisioneros, en distintos momentos de la dictadura y la transición. Se trata del impulso narrativo por el cual estas personas decidieron voluntariamente y bajo sus propias palabras, hacer memoria y relatar sus experiencias, sin la intermediación de terceros que solicitaran sus declaraciones. Estos son: Cerco de púas de Aníbal Quijada (1990), Dawson de Sergio Vuskovic (1984), Dawson de Aristóteles España (1985), Dawson Isla 10 de Sergio Bitar (2011) y Retorno a Dawson de Miguel Lawner (2004).

Aníbal Quijada y Aristóteles España fueron prisioneros políticos de la ciudad de Punta Arenas, el primero era militante comunista detenido a la edad de 55 años, mientras el segundo se transformó en uno de los presos más jóvenes de Dawson al ser detenido a los 17 años cuando ejercía como dirigente estudiantil de la Juventud Socialista. Por su parte, Sergio Bitar, Miguel Lawner y Sergio Vuskovic, integraban el contingente de presos llevados desde la zona central y que ocupó cargos en la administración del gobierno de la Unidad Popular. Bitar era ministro de Minería y militante de la Izquierda Cristiana, Lawner era director ejecutivo de la Corporación de Mejoramiento Urbano (CORMU)y Vuskovic era alcalde de Valparaíso, ambos militantes del Partido Comunista.

Las obras de Aníbal Quijada y Aristóteles España comparten un valor político y literario (Peris Blanes, 2009b), ya que no solo cumplen con una función de denuncia, sino que despliegan un propósito literario, que les hizo acreedoras de reconocimientos internacionales ${ }^{10}$. El libro de Quijada se estructura en dos partes, la primera bajo la forma de un diario en el que se relatan los acontecimientos vividos por personajes anónimos en el campo de prisioneros; la segunda, como un relato de ficción protagonizado por perros que esperan a sus amos atrapados por los militares, dando cuenta de lo que ocurre en la ciudad, fuera del campo. Por su parte, la obra de España es un poemario escrito durante su presidio en los campos de isla Dawson, entre septiembre de 1973 y septiembre de 1974.

Isla Dawson, testimonios de oprobio y dignidad, de Abel Esquivel Querci.

10 En 1977 Cerco de púas recibió el Premio Casa de las Américas en el género Testimonio y en 1985 Dawson fue galardonado con el Premio Rubén Darío. 
Los testimonios de Sergio Bitar y Miguel Lawner ofrecen un relato de lo sucedido desde su detención en Santiago hasta el abandono de la isla, describiendo similares episodios y situaciones parecidas, ya que ambos permanecieron detenidos junto a Vuskovic, en el sector del campo destinado a autoridades del gobierno de la Unidad Popular. El testimonio de Bitar narra también el paso final por el campo de Puchuncaví tras la salida de Dawson. Lawner agrega a su relato información sobre la isla extraída de otras fuentes y la referencia a otros testimonios ya publicados. Al igual que Bitar, incorpora anexos con documentos y un pasaje final sobre el retorno de los ex prisioneros en un viaje conmemorativo el año 2003. Por su parte, el texto de Vuskovic hace uso de diversos recursos narrativos que intercalan fragmentos poéticos, relato de rutinas y hechos a través de episodios señalados por fechas u horas del día, junto a la reproducción de fragmentos de declaraciones $y$ testimonios entregados por ex prisioneros en distintos contextos luego de la liberación, varios de ellos publicados en "Denuncia y Testimonio" (Comisión Internacional de Investigación de los Crímenes de la Junta Militar en Chile, 1975).

\section{LA ISLA COMO CAMPO Y LIBERACIÓN}

Como otros testimonios de prisión política durante la dictadura chilena, los testimonios del presidio en isla Dawson ofrecen un relato que narra y describe la experiencia de la detención, las condiciones de vida en los campos, incluyendo la relación entre los presos, y entre éstos y sus captores, en el marco de un escenario constituido por los espacios propios del encierro, tales como barracas, comedores o "rancho", estrechos patios y precarios recintos o lugares destinados a la higiene. Adicionalmente, las condiciones del presidio en Dawson incluyen el tránsito y la circulación por distintos parajes de la isla, donde los presos, siempre bajo estricta vigilancia y asedio, realizan trabajos forzados como parte del castigo que el nuevo régimen les ha impuesto, en su condición de vencidos.

11 Nótese que para quienes llegaban desde la zona central del país, en el mes de septiembre la primavera ya comenzaba a anunciarse.

12 Esta irónica situación no pasa inadvertida. "Ahora, como
El contacto con los extramuros del campo permitealosprisioneros percibir con mayoramplitud sensorial los indicios del contexto geográfico, que desde su llegada a la isla ha comenzado a impactar su experiencia. "Me equilibro con dificultad y de pronto percibo que estamos pisando nieve. No puedo creerlo... nieve, pero si es nieve" (Lawner, 2004, p. 18 $)^{11}$. Para el contingente de detenidos llevados desde Santiago, el trayecto a Dawson es tan confuso como desconocido, incluyendo el viaje en distintos transportes hasta su destino final. Solo el recuerdo de José Tohá que, en su calidad de ministro de Defensa, había hecho entrega de la isla a la Armada el año antes del Golpe, permite la localización en el mapa y la restitución de un nombre para el lugar: isla Dawson ${ }^{12}$. De ahí en adelante la isla se hará presente en los distintos pasajes de los testimonios, ya sea como viento que se cuela en las barracas, lluvia que golpea las cabezas o las nubes que en su tránsito daban paso al azul del cielo.

El carácter insular de la geografía sumado a un clima subantártico azotan la existencia de los que alli permanecen cautivos y literalmente aislados.

El clima era muy frío y ventoso. Dawson está más al sur que las Malvinas en una latitud que equivale en el Hemisferio Norte a alguna zona de Siberia o Alaska, donde por coincidencia, hay una región que también se llama Dawson (Bitar, 2011, p. 57).

En el inicio del presidio, la mayor amenaza es congelarse y enfermar en condiciones de aislamiento e incomunicación, situación agravada por la imposición del trabajo forzado, ya sea para contribuir a la subsistencia del campo o a distintas faenas de urbanización de la isla y su poblado. Así, prontamente la topografía y el clima unidos a las tareas pesadas, causan estragos en la condición corporal de los prisioneros:

\section{(...) se nos han impuesto tareas muy pesadas, como cargar al hombro}

una forma de agradecimiento militar, se utilizaba para confinar presos políticos, entre los cuales habían varios que aprobaron la expropiación" (Quijada, 1990, p. 135). 
sacos rellenos de ripio que debemos transportar desde la playa, ascendiendo por empinadas laderas, y depositarlo en las gradas de la escalera que sube en zigzag hasta la cumbre de los acantilados. Es una faena de esclavos, azuzados constantemente por los gritos de los guardias. Aun cuando llueva, estamos obligados a continuar cuesta arriba en medio del fango. (...) Debiera ser nuestro último ascenso del día, y nos duele todo el cuerpo, en especial los muslos, fatigados por el esfuerzo de subir y bajar el cerro (Lawner, 2004, p. 108).

Por la rutina del trabajo impuesto, los límites del campamento se extienden a playas, turberas y bosques quemados, recuperándose en el recuerdo un lenguaje que se igualaba con los recursos del espacio.

Durante los primeros meses en COMPINGIM, se agregaron esporádicamente otros dos o tres trabajos a los que ya teníamos. A uno le llamábamos 'ir a bolones'. Nos llevaban en un camión tolva a ciertos lugares de la playa, donde se hallaban piedras redondeadas, grandes, que debiamos ir seleccionando y echando al vehículo (...) Otro trabajo era 'ir a turba'. En algunas zonas de gran humedad se va formando una capa vegetal de helecho que después de algunos años se pudre, transformando el lugar en una zona casi pantanosa (...) Para hacer ese trabajo, debiamos meternos en esa verdadera ciénaga, con unas botas que a veces los encargados nos prestaban, o con nuestros propios zapatos. De cualquier manera, salíamos embarrados y malolientes (Bitar, 2011, p. 58).

La disposición de la espacialidad concentracionaria es reforzada con las características geográficas del lugar en que se ha emplazado el campo, cuyas condiciones son idóneas para servir a los propósitos de un cautiverio:

Llegamos al campamento, a los nuevos pabellones. Éstos enfrentaban la playa y las construcciones en fila se internaban en esa entrada de costa que moría a pocos metros en el acantilado o escarpa. En lo alto podían distinguirse numerosas casetas y el brillo de armas largas (Quijada, 1990, p. 141).

El trabajo forzado junto a la disposición espacial y estructura del recinto remiten al imaginario de los campos de concentración del nazismo. Así lo describen distintos testimonios, y lo corrobora la expresión de uno de los oficiales a cargo:

Después del capitán Zamora apareció el capitán Varas, también del Ejército, un hombre directo y afable. Lo retrata la frase que usó al día siguiente de su llegada a Dawson, cuando se sentó con nosotros y habló con espontaneidad: 'Puchas, qué impresionante es esto: igual que los campos de concentración que he visto en las películas... (Bitar, 2011, p. 131).

Estas condiciones hacen que el escape sea imposible y que las constantes amenazas ante un intento de fuga resulten absurdas para los prisioneros. A la vez los testimonios hacen notar otra dimensión en la cual la violencia ha quedado unida a las condiciones geográficas del extremo sur, al padecer episodios de tortura en los cuales la naturaleza es puesta al servicio de la agresión:

A algunos los colgaban de sogas y los sumergían en el canal de Magallanes. Los dejaban un rato, los volvían a sacar $y$ asi continuaban. Otros narraron que los hacian correr con los pies desnudos sobre unas matas de calafates, que son tan espinudas como las zarzamoras (Bitar, 2011, p. 124).

Este mismo episodio se encuentra en Vuskovic (1984) “(...) también nos amarraron desnudos y nos arrastraron por encima de las espinudas matas de calafate" (p. 70). Por su parte, las imágenes poéticas contenidas en la obra de España vuelven toda experiencia de naturaleza 
como una marca de violencia: "Caminamos vendados por la arena, /la arena es un clavo que hiere" (No hay más dolor bajo los árboles) (España, 1985, s/n).

Esta representación de la geografía concomitante a la violencia crea imágenes de un particular paisaje de naturaleza militarizado. Mediante el recurso literario de la copresencia de elementos de dos universos simbólicos disímiles, la naturaleza y del mundo militar referido a los sujetos, los objetos y la tecnología represiva, se genera una realidad dual de superposición: "Un camino con piedras y soldados" (Llegada) (España, 1985, s/n). La presencia del elemento militar en la naturaleza es amenazante y progresivamente se vuelve más agresivo: "Nos llevan a cortar leña por los bosques / de sol a sol,/ custodiados por patrullas / que apuntan directamente a la cabeza" (Caminos) (España, 1985, s/n). De esta manera la representación de la naturaleza pierde sus atributos simbólicos tradicionales y su capacidad de resguardar una externalidad respecto del mundo militar.

En esta operación lingüística y representacional, España opta por no elaborar un espacio de naturaleza intocado, externo, ajeno a las condiciones históricas, sino que ejecuta lo inverso: le confiere poder totalitario a la fuerza de la naturaleza, esto implica radicalizar la experiencia de la violencia y las formas del castigo mediante la inscripción de lo militar en lo natural, y no dejar espacio "afuera" del campo concentracionario. La relación de simetría entre el poder de la naturaleza y el poder militar llega a un punto álgido en el verso "Tal vez mañana llueva / o apaleen a alguien" (Gotas que caen). La relación sintáctica disyuntiva no solo plantea una coordinación entre los verbos llover y apalear, sino que también una correlación de sujetos elididos. Por otra parte, esta elisión de un espacio ajeno al campo es abolida en términos de la misma posibilidad de representación, porque la propia naturaleza es víctima del campo de exterminio que define al paisaje: "Hay olor a nubes enterradas" (Caminos).

Así como el paisaje duele por la imposición de tareas extremas y las constantes amenazas, la posibilidad de entrar en contacto con los alrededores también supone vivir el encierro de otra forma, sobre todo para aquellos detenidos de la región que habían permanecido en recintos donde se ejercía un régimen de tortura y violencia permanente:

Ese primer día fuimos casi todos a buscar troncos. Queríamos salir y conocer el bosque. Marchamos en fila, escoltados. Eran casi dos kilómetros desde el pabellón. Torciendo por un sendero se internaba luego hacia los montes próximos. Alcanzamos el río donde ya habían varios prisioneros y soldados trabajando en una represa. A poco andar, estuvimos entre los árboles (Quijada, 1990, p. 147).

En el relato de Vuskovic la dimensión benéfica de la experiencia en la isla ha quedado expresada en pasajes que emulan al género de la oda para alabar el entorno. De varios, el más elocuente se titula "La isla era hermosa" (p. 116) en el que funde la descripción de la naturaleza insular y su historia humana y geográfica, la que según el autor se opone a las descripciones bucólicas de nenúfares y cisnes de cuello negro, pero impregnada de otros sentidos de belleza. Vuskovic intercala estos pasajes en medio de la descripción de las rutinas presidiarias y de los testimonios de otros prisioneros, por tanto, el efecto paradojal de esa experiencia de presidio se aprecia en la totalidad de la obra, mientras que en otros casos como en el testimonio de Bitar, ello forma parte de una reflexión sobre lo vivido:

Porque, a pesar de la situación en que nos encontrábamos, a ratos nos sentíamos absortos por la belleza de la isla, de la costa, de las playas de guijarros y las estepas: un prado de color muy claro, casi amarillo, que es tierra quitada de los bosques. En las zonas donde había árboles, el verdor llegaba casi hasta el mar. Percibir la vastedad y la calma estando en prisión, nos daba mayor tranquilidad y paz. Nos deslumbraba la belleza de las nubes, sus configuraciones y colores que inducían a hundirse en un mundo mágico (Bitar, 2011, p. 99).

Estas descripciones del entorno alcanzan también a la fauna presente en la isla, la que 
produce admiración y asombro. De esta forma, el espacio geográfico, liberado por un instante de la presencia militar, permite el acceso a un estado contemplativo a partir del cual emerge una escritura naturalista de sus riquezas y recursos:

En la playa también era hermoso el espectáculo de las toninas overas, los delfines más bellos de nuestros mares (...) Con frecuencia, mientras trabajábamos cerca del mar y a muy pocos metros, veíamos grupos de cuatro o cinco, que empezaban a danzar, daban grandes saltos, salian de cuerpo entero, se zambullian y volvían a emerger (Bitar, 2011, p. 119).

En el testimonio de Vuskovic, la radicalización del estado contemplativo que conlleva una elaboración poética de las dimensiones existenciales y metafísicas, que se aprecia en el sujeto de la enunciación que se inscribe como un hablante lírico que actualiza formas más tradicionales de la prosa poética: "He aquí la naturaleza toda cubierta de blanco (...) ¿Será eterna esa apariencia, será pasajera? (...) ¿Acaso también el corazón se transformará en blanco y frío yermo?" (Vuskovic, 1984 , p. 34). De esta forma, el autor refiere elementos del espacio geográfico a través de un lenguaje poético, en el que destacan los usos metafóricos. En varios apartados del testimonio, la representación de la geografía y de la naturaleza supera la referencia concreta a la isla Dawson para adentrarse con una elaboración arquetípica de la naturaleza. En ese devenir, el texto elabora espacios metafísicos en los que se hace posible un diálogo sobre el sentido de elementos de naturaleza más globales, lo que permite la apertura hacia la reflexión filosófica.

En su regreso a Dawson el año 2003 en un viaje conmemorativo, Sergio Bitar anota:

¿Qué quedaba de todo aquello donde tanto sufrimos? Avistaba de nuevo ese paisaje frío y gris, algo desolador, el viento, los árboles torcidos. Pero no era el mismo paisaje. No eran los mismos

13 Para el caso del campamento de Río Chico éste efectivamente sufrió transformaciones radicales, puesto que marinos. No era el mismo país. Nosotros no éramos los mismos (Bitar, 2011, p. 217).

Treinta años después, la memoria no ha podido eludir la omnipresencia del entorno geográfico, que en los ya lejanos días de presidio pasó a ser constituyente de la experiencia de reclusión en isla Dawson. El paisaje del recuerdo retorna para confrontar al paisaje del presente, y dado que el contexto ha variado -el país, las personas, la materialidad-, la atribución de significado sobre el espacio habría cambiado produciendo entonces un nuevo paisaje ${ }^{13}$.

\section{HACIA UNA MEMORIA GEOGRÁFICA DEL PRESIDIO POLÍTICO}

Los testimonios de presidio político en isla Dawson nos han permitido abordar aspectos escasamente trabajados en los análisis sobre las memorias de víctimas de la violencia política desplegada por la dictadura cívico-militar en Chile, cual es el papel del contexto geográfico en las condiciones de la experiencia del presidio y en el recuerdo que de éste hacen ex prisioneros de guerra a través de sus relatos. De esta forma al representar las características climáticas, topográficas y ecológicas de la isla, como un paisaje del recuerdo, estos relatos aportan una memoria geográfica en el marco de las memorias del presidio político.

La incorporación de las cualidades climáticas y topográficas de la isla como parte de la experiencia y recuerdo de las faenas y trabajos forzados a los que fueron sometidos los prisioneros, constituye un paisaje que, derivado del encuentro cuerpo a cuerpo con el frío, la lluvia, el viento y la nieve, los terrenos fangosos de las turberas, la pesadez de la arena y la dificultad de laderas escarpadas, se manifiesta como una experiencia sensorial y emocional (Cano, 2015) de la geografía extrema que caracteriza tanto a la isla como a la violencia que los captores dejaron caer sobre sus cautivos.

El contexto geográfico como parte constitutiva de la violencia dictatorial en una situación de presidio político, pone de relieve la importancia 
del espacio como marco (Halbwachs, 2004a) para la construcción de memorias en quienes compartieron esta experiencia límite. En ellas la isla se ha transformado en un gran campo de prisioneros, cercado por las gélidas aguas del estrecho de Magallanes. Sin embargo, así como la geografía se recuerda al servicio de la agresión como parte del paisaje del campo desde el lugar del prisionero, otras posiciones adoptadas por el sujeto de la enunciación en la representación del espacio geográfico, ofrecen nuevas dimensiones para la experiencia y el recuerdo del presidio. El afán de referencia objetiva en la representación de la naturaleza como externalidad del campo de prisioneros, implica un espacio de libertad para quien puede contemplar. Se trata de un narrador impresionado y deslumbrado ante la naturaleza, la cual queda plasmada mediante una escritura que crea un paisaje pictórico que enfatiza los aspectos visuales, la referencia a luces, tonalidades y colores. Es en estos segmentos narrativos donde se presenta una cesura de la condición del presidiario y se expone una posición contemplativa que expresa "la elaboración del evento traumático como una economía y una poética de la mirada" (Fischer, 2012, p. 289), en la cual los narradores aparecen absortos, pacificados y liberados del mundo de violencia al que han sido arrojados, potenciando la apertura hacia otra dimensión existencial.

Los testimonios presentan, entonces, una recuperación paradójica de las condiciones geográficas como parte del ser cautivo y que, en el marco más amplio de las memorias del terrorismo de Estado, constituye un tipo particular de memoria del presidio geográfico; primero, por la relevancia del contexto espacial y geográfico para el recuerdo; y luego, por la coexistencia de recuerdos de subyugación y violencia, junto a experiencias de resiliencia y liberación, que se producen gracias al contacto con la geografía de la isla ${ }^{14}$. En esta memoria se configura una subjetividad cautiva y a la vez cautivada por la isla, como dimensiones concomitantes, lo que incluso podría ser entendido como una forma de subvertir

14 Es probable que, en testimonios de prisioneros de otros campos emplazados en contextos geográficos extremos, como Chacabuco y Pisagua en el norte de Chile, donde las rutinas de presidio posibilitaran el contacto con el entorno, encontremos también la elaboración de esta memoria del presidio geográfico. el arrasamiento humano que se propuso ejecutar la dictadura sobre los vencidos. O como señalan González y Montealegre (2017), en el recuerdo de la prisión política chilena puede coexistir el imaginario de los campos de concentración nazis "con la construcción de un realitario que se hace efectivo en la sobrevivencia cotidiana" (p. 66).

Se diría que la dimensión restaurativa o compensatoria que se advierte en estas memorias, constituida por experiencias de cierta resiliencia como la contemplación de las bellezas naturales, y distanciadas del componente trágico de las memorias del terrorismo de Estado, resultan menos funcionales a la denuncia y a una memoria del horror (Montealegre, 2013, 2018), sin embargo hoy podrían ser audibles en virtud de un contexto capaz de reconocer diversas dimensiones de la victimización, entre ellas las distintas formas a través de las cuales fue posible sobrellevar la violencia extrema. Como señala Montealegre (2018) se trata de "diversas formas en que se puede manifestar la sobrevivencia. Entre ellas las acciones desarrolladas desde la comunidad cautiva, sean de resistencia o autocuidado, de contención o de contienda; estrategias de adaptación que, en términos generales, son parte de procesos de resiliencia que trascienden la búsqueda de la mera supervivencia física" (p. 409).

Finalmente, las memorias del presidio geográfico componen una relación entre espacio y memoria que trasciende los usos conmemorativos del espacio en el presente a través de la producción de lugares de memoria, proponiendo entonces una espacialidad recordada, es decir, la elaboración de un paisaje del recuerdo, y no solo un "paisaje de memoria" como podría entenderse en la actualidad la acción de recuperar recintos de detención, para erigir alli monumentos y memoriales ${ }^{15}$.Esto abre la posibilidad de ampliar la relación entre espacio y memoria, inaugurando un ámbito de estudios en el cual se encuentren el análisis espacial aportado por la geografía y el interés por los procesos de recuerdo propio del campo de estudio de las memorias colectivas.

15 El lugar de emplazamiento del antiguo campo de Río Chico fue protegido legalmente como patrimonio por el Estado chileno el año 2010, al declararlo Monumento Nacional. Posteriormente se propuso edificar alli un memorial que recuerda la existencia del campo y rinde homenaje a sus víctimas (Valencia, 2015). 


\section{AGRADECIMIENTOS}

Agradecemos a los/as evaluadores/as por los comentarios recibidos, ya que ellos han contribuido a enriquecer nuestro texto. También a Iván González, de la Agrupación de Familiares de Ejecutados Políticos de Magallanes, quien con sus comentarios contribuyó a precisar información y sugerir fuentes.

\section{BIBLIOGRAFÍA}

Achugar, H. (1992). Historias paralelas / Ejemplares: La historia y la voz del otro. Revista de Crítica Literaria Latinoamericana, 18(36), 51-73.

Alderman, D. H., \& Inwood, J. F. J. (2013). Landscapes of Memory and Socially Just Futures. En N. C. Johnson, R. H. Schein \& J. Winders (Eds.), The Wiley-Blackwell Companion to Cultural Geography (pp. 186-197). John Wiley \& Sons. Ltd.

Andermann, J. (2008). Paisaje: imagen, entorno, ensamble. Orbis Tertius. Memoria Académica, 13(14), 1-8.

Andermann, J. (2012). Expanded Fields: Postdictatorship and the Landscape. Journal of Latin American Cultural Studies, 21(2), 165-187.

Astaburuaga, F. (1899). Diccionario geográfico de la República de Chile.

Barticevic, M. (2009). Esperanza en el austro. Memorias de prisión política en Magallanes. Santiago de Chile: Mosquito Comunicaciones.

Beverley, J. (1993). El testimonio en la encrucijada. Revista iberoamericana, 59(164), 485-495.

Bitar, S. [1987] (2011). Isla 10. Santiago de Chile: Ed. Pehuén.

Cabeza, A., Cárdenas, A., Lawner, M., Seguel, P., \& Bustamante, J. (2017). Patrimonio de la memoria de los derechos humanos: Sitios de memoria protegidos como monumentos nacionales 1996-2016. Santiago de Chile: Dirección de Bibliotecas, Archivos y Museos.

Cano, N. (2015). Corporalidad y memoria en el paisaje cotidiano. Alteridades, 25(49), 39-52.

Comisión Internacional de Investigación de los Crímenes de la Junta Militar en Chile (1975). Tercera Sesión, Ciudad de México, 18-21 de febrero.

Concha, J. (1978).Testimonios de la lucha antifascista. Revista Araucaria, 4, 129-147.

Da Silva Catela, L. (2010). Exponer lo invisible. Una etnografía sobre la transformación de Centros Clandestinos de Detención en Sitios de Memoria en CórdobaArgentina. En Recordar para pensar, memoria para la democracia. La elaboración del pasado reciente en el Cono Sur de América Latina (pp. 44-56). Santiago de Chile: Ed. Böll Cono Sur.

Da Silva Catela, L. (2013). Prólogo. En Ana Guglielmucci. La consagración de la memoria. Una etnografía acerca de la institucionalización del recuerdo sobre los crímenes del terrorismo de Estado en la Argentina (pp. 9-12). Buenos Aires: Antropofafia.

Dawson 2000. (2003). Campos de concentración y centros de detenciones $y$ en Magallanes 1973 -1977. Recuperado de: http://www.dawson2000.com/elie7. htm

Dwyer, O. J., \& Alderman, D. H. (2008). Memorial landscapes: analytic questions and metaphors. GeoJournal, 73(3), 165-178.

Epple, J. A. (1994). Acercamiento a la literatura testimonial de Chile. Revista Iberoamericana, 60(168), 1143-1159.

España, A. [1980] (1985). Dawson: poemas escritos en el campo de concentración de Isla Dawson, septiembre 1973 - septiembre 1974. Santiago de Chile: Ed. Bruguera.

Esquivel, A. (2013). Isla Dawson, testimonios de oprobio y dignidad. Santiago de Chile: Editorial Copygraph.

Fischer, M. L. (2012). Poéticas de la mirada en Frazadas del Estadio Nacional de Jorge Montealegre. Confluenze. Rivista di Studi Iberoamericani, 4(2), 288-296.

Foote, K. E., \& Azaryahu, M. (2007). Toward a geography of memory: geographic dimensions of public memory and commemoration. Journal of Political and Military Sociology, 35(1), 125-144.

García, J. (2009). Lugares, paisajes y políticas de memoria: una lectura geográfica. Boletín Boletín de la Asociación de Geógrafos Españoles, 51, 175-202.

Geopoetics: Space, Place, and Landscape. (2000). Critical Inquiry, 26(2), 173-174.

González, I. (2016). Justicia Transicional en Magallanes. Una Memoria no escrita. Presentado en VII Conferencia Internacional de Educación en Derechos Humanos "Los Desafíos de la Sociedad Civil", Santiago de Chile.

González, S., \& Montealegre, J. (2017). Imaginario y relatitario: juego social en la prisión política, Gradiva, VI(1), 6171.

Halbwachs, M. (2004a). La memoria colectiva. Zaragoza: Prensas Universitarias de Zaragoza.

Halbwachs, M. (2004b). Los marcos sociales de la memoria. España: Anthropos.

Hoelscher, S., \& Alderman, D. H. (2004). Memory and place: geographies of a critical relationship. Social \& Cultural Geography, 5, 347-355. 
Jara, R., \& Hernán Vidal (Eds.). Testimonio y literatura. Minnesota: Institute for Study of Ideologies and Literature, 1986.

Jelin, E. (2002). Los trabajos de la memoria. Madrid: Siglo XXI de España Editores: Social Science Research Council.

Lawner, M. (2004). Retorno a Dawson. Santiago: LOM Ediciones.

Legoupil, D., Christensen, M., \& Morello, F. (2011). Una encrucijada de caminos: el poblamiento de la Isla Dawson (Estrecho de Magallanes). Magallania (Punta Arenas), 39(2), 137-152.

Leppe, M., Domínguez, D. E., Olave, C., \& Rodrigo, C. (Septiembre de 2007). Revisión de las islas subantárticas de Chile austral. Presentado en VI Simposio Argentino y III Latinoamericano sobre Investigaciones antárticas. Ms.

Lowenthal, D. (1998). El pasado es un país extraño. Madrid: Ed. Akal.

Martinic, M. (2011). Centenario del cierre de la misión de Dawson: Reflexiones sobre un esfuerzo admirable $e$ infructuoso. Magallania (Punta Arenas), 39(2), 97103.

Martinic, M. (1999). Dawsonians o Selkkar: Otro caso de mestizaje aborigen histórico en Magallanes. Anales del Instituto de la Patagonia, 27, 79-88.

Mate, G. (2010). Memory: how people remember the landscape. Recuperado de http://www.qhatlas.com. au/essay/memory-how-people-remember-landscape

Ministerio de Defensa Nacional. (2017). Temas destacados, Isla Dawson. Recuperado de https://www.defensa.cl/ temas-destacados/isla-dawson/

Montealegre, J. (2013). Memorias eclipsadas. Duelo y resiliencia comunitaria en la prisión política. Santiago de Chile: Asterión.

Montealegre, J. (2018). Derecho a fuga. Una extraña felicidad compartida. Santiago de Chile: Asterión.

Museo virtual de la Memoria y los Derechos Humanos de Magallanes (2019). Isla Dawson. Recuperado de: https://memoriamagallanes.cl/isladawson/\#relatos

Narváez, J. (1988). La invención de la memoria. Santiago de Chile: Pehuén.

Nora, P. (2009). Pierre Nora en Les lieux de memoire. Santiago de Chile: LOM Ediciones.

Peris Blanes, J. (2005). La Imposible Voz: Memoria y Representación de los Campos de Concentración en Chile: La Posición del Testigo. Santiago de Chile: Editorial Cuarto Propio.

Peris Blanes, J. (2009a). Combatientes de un nuevo cuño: supervivencia y comunidad en los primeros testimonios del exilio. Universum, 24(1), 144-161.

Peris Blanes, J. (2009b). Una poética de las ruinas: testimonio y alegoría de Aníbal Quijada. Revista chilena de literatura, 74, 99-121.

Peris Blanes, J. (2011). Un viaje por el infierno, de Alberto Gamboa: escritura testimonial e imaginario de la reconciliación. Literatura y lingüística, 24, 81-96.

Pizarro, C. (2016). Voces que incomodan. El silenciamiento del testimonio en postdictadura. En C. Pizarro y J. Santos (Eds.), Revisitar la catástrofe. Prisión política en el Chile dictatorial (pp. 35-48). Santiago de Chile: Ed. Pehuén-Instituto de Estudios Avanzados USACH.

Pollak, M. (2006). Memoria, olvido, silencio, la producción social de identidades frente a situaciones límite. Buenos Aires: Ediciones Al Margen.

Quijada, A. [1977] (1990). Cerco de Púas. Un candente testimonio de la represión. Santiago: Rodma Comunicaciones: Eds. Fuego y Tierra.

Rapaz, J. (2000). Isla Dawson. Algo más que soberanía... Revista Marina, 117(859), 1-9.

Rodríguez, M. (2013). Notas para una historia infamante de la isla Dawson en la Patagonia - Primera Parte. Recuperado de http://sur-historia.blogspot.com/2013/06/notaspara-una-historia-infamante-de-la.html

Santos, J. (2017). Intelectuales en prisión. Resistencia cultural en los espacios del terror de la dictadura chilena. Palimpsesto. Revista Cientifica de Estudios Sociales Iberoamericanos, 8(11), 019-036.

Schindel, E., \& Colombo, P. (Eds.). (2014). Space and the Memories of Violence. Landscapes of Erasure, Disappearance and Exception. Palgrave Macmillan. Recuperado a partir de http://www.palgrave.com/us/ book/9781137380906

Schlatter, R. P., \& Schlatter, J. E. (2004). Los turbales de Chile. En Los Turbales de la Patagonia. Bases para su inventario y la conservación de su biodiversidad, Publicación (pp. 75-80). Recuperado de http://www. limne.cl/ltdlp/tdlp-p3.pdf

Skewes, J. C., Guerra, D., Rojas, P., \& Mellado, M. A. (2011). ¿La memoria de los paisajes o los paisajes de la memoria? Los enigmas de la sustentabilidad socioambiental en las geografías en disputa. Memória das paisagens ou paisagens da memória. Desenvolvimento e Meio Ambiente, 23, 39-57.

Valencia, N. (2015). Memorial de Tierra del Fuego en isla Dawson busca recordar a torturados en campos de concentración. Recuperado 12 de junio de 2017, a partir de http://www.plataformaarquitectura.cl/ 
cl/760306/memorial-de-tierra-del-fuego-en-isladawson-busca-recordar-a-torturados-en-campos-deconcentracion

Vuskovic, S. [1980 en italiano] (1984). Dawson. Madrid:
Ediciones Michay.

Winn, P. (Ed.). (2014). No hay mañana sin ayer: batallas por la memoria histórica en el Cono Sur. Santiago de Chile: LOM Ediciones. 